\title{
MODELO DE REALIDAD VIRTUAL \\ DEL CENTRO HISTÓRICO DEL \\ DISTRITO CENTRAL BASADO EN \\ ANÁLISIS ESPACIAL CON SISTEMAS DE \\ INFORMACIÓN GEOGRÁFICA (PARTE II)
}

Eduardo L. Moreno Segura

Departamento de Ciencia y Tecnologías de la Información Geográfica,

Facultad de Ciencias Espaciales, Universidad Nacional Autónoma de Honduras.

eddmorse7@gmail.com

\section{Resumen}

El presente proyecto es la continuidad al proyecto Modelo de realidad virtual del centro histórico del Distrito Central basado en análisis espacial con el SIG para la gestión de centros históricos desarrollado en el marco de la beca básica de investigación No.07-BBI-2007, patrocinada por la Dirección de Investigación Científica de la UNAH. El propósito de este proyecto es mostrar recorridos interactivos y de realidad virtual en 3D referentes al estado de conservación de las principales edificaciones consideradas patrimonio histórico y arquitectónico dentro del límite del centro histórico del Distrito Central. Con el fin, además, para proponer y promover proyectos de conservación educativos y turísticos así como de mejoramiento y desarrollo que tengan dentro de su área de estudio el centro histórico de Tegucigalpa y Comayagüela. En esta nueva fase del proyecto, se incorpora como área de estudio y aplicación metodológica, las edificaciones comprendidas dentro del campus de la Ciudad Universitaria, con miras a contribuir al proceso de plan maestro de desarrollo físico de la UNAH, ordenamiento territorial y gestión de los mismos. 
La visualización fotorrealística 3D se aplica a áreas como la arquitectura, arqueología, cartografía, ingeniería civil, medicina, entre otras, y como herramienta de investigación, conservación, gestión y divulgación de patrimonio histórico y turístico. Tal es el caso de los modelos generados en este proyecto, los cuales pueden ser usados por técnicos y restauradores con el fin de hacer estudios, análisis o futuras predicciones sobre planes de actuación.

Palabras clave: Centro histórico, realidad virtual, modelo 3D, sistemas de información geográfica.

\section{Abstract}

This project is to continue the project virtual reality model of the Central District Historical Center based on spatial analysis with GIS for the Management of Historic Centres developed in the framework of the Basic Research Grant No.07-2007 $\mathrm{BB}$-sponsored Scientific Research Directorate of the UNAH. The purpose of this project is to show paths of virtual reality and interactive $3 \mathrm{D}$, concerning the state of conservation of the main buildings considered historic architectural heritage within the limits of the Central District Historical Center also serve to propose and promote conservation projects, educational and tourism as well as improvement and development that are within your area of study the History Center Comayagüela Tegucigalpa and also in this new phase of the project is incorporated as an area of study and methodological application to buildings on campus including the City University in order to contribute to the process of physical development master plan of the UNAH, Land Planning and managing them.

The 3D photorealistic visualization is applied in areas such as architecture, archeology, cartography, civil engineering, medicine among others, and as a tool for research, conservation, management and dissemination of cultural heritage and tourism. Such is the case of the models generated in this project, which can be used by technicians and restorers in order to make studies, analyzes or predictions about future action plans.

Keywords: Historical center, virtual reality, 3D model, GIS 


\section{Introducción}

La investigación -importante activo capaz de hacer avanzar el desarrollo de metodologías que integran las tecnologías de información y de visualización en 3D aplicadas al ámbito de variedad de disciplinas como son la arquitectura, la historia, la planificación urbana, ordenamiento territorial o simplemente aplicadas al conocimiento de la ciudad-, es nuestro punto de partida en este trabajo.

Se sabe que las tecnologías de realidad virtual compatibles con las de un Sistema de Información Geográfica (SIG), proporcionan a los investigadores la infraestructura fundamental para comenzar a construir ciudades virtuales que pueden recrear un entorno interactivo de simulación y análisis de los lugares urbanos con auténtico realismo, y a la vez pueden integrar todo el conjunto de parámetros medioambientales (físicos sociales y económicos) que requiere la planificación urbana.

En esta nueva fase del proyecto Modelo de realidad virtual del centro histórico del Distrito Central basado en análisis espacial con Sistemas de Información Geográfica, parte II, aplicamos la metodología diseñada a nuevas áreas de estudio como ser el campus de Ciudad Universitaria de la UNAH, obteniendo modelos tridimensionales y fotorrealistas cuyos aportes de información contribuirian a las investigaciones y proyectos desarrollados para el ordenamiento territorial, la gestión, conservación de edificios y desarrollo del centro histórico, así como la posibilidad de verlos proyectados de una forma comprensible e interactiva, dando paso a una buena promoción y divulgación educativa en diferentes niveles del conocimiento.

\section{Metodología}

Basado en la metodología desarrollada en la primera fase de este proyecto, se aplicó la misma de la siguiente manera:

\section{Identificación y selección del área de estudio}

En esta nueva fase del proyecto se seleccionaron dos áreas de estudio para la aplicación de la metodología:

Centro histórico de Tegucigalpa: Se añadió a los trabajos en el centro histórico del Distrito Central de Honduras hechos en la primera fase del proyecto. Las edificaciones fueron seleccionadas por su relevancia y trascendencia histórica. Estas fueron: edificio de la Catedral de Tegucigalpa, Iglesia "Los Dolores" de Tegucigalpa, 
antigua Casa Presidencial (Museo Histórico de la República), Teatro Nacional "Manuel Bonilla" y el edificio del Congreso Nacional.

Ciudad Universitaria (UNAH): En esta nueva fase del proyecto, se agregó como área de estudio los edificios más emblemáticos dentro del campus Ciudad Universitaria de la Universidad Nacional Autónoma de Honduras (antigua nomenclatura de edificaciones): Vicerrectoría de Orientación y Asuntos Estudiantiles (VOAE), edificio de Registro, Auditorio Central, edificio de Química y Farmacia, edificio 1, Facultad de Derecho, edificio L1, edificio L2, Facultad de Ciencias Económicas, edificio 6 , edificio de aulas 4A y 4B, edificio administrativo, Facultad de Ciencias Espaciales (FACES) ${ }^{4}$.

Levantamiento, ubicación geográfica y fotografías de fachadas de todas las edificaciones seleccionadas en el área de estudio

En esta actividad se realizó un trabajo de campo donde fue necesario fotografiar (Figura 2.1) y medir cada una de las edificaciones dentro del campus universitario; se evitó en la mayor medida la perspectiva visual, para solamente capturar los detalles en forma orthogonal. En los casos en que fue posible, se solicitaron los planos de fachadas de las edificaciones y monumentos para una mejor proyección. Para las edificaciones seleccionadas en el centro histórico este proceso ya se había realizado en la primera parte del proyecto.

4 En la actualidad, la nomenclatura de los edificios es la siguiente: Edificio de Química y Farmacia (E1), edificio 1 (A1), edificio L1 (B1), edificio L2 (B2), edificio 6 (C3), edificio de aulas 4A (F1) y 4B (D1). Se puede ver el mapa completo más adelante. 


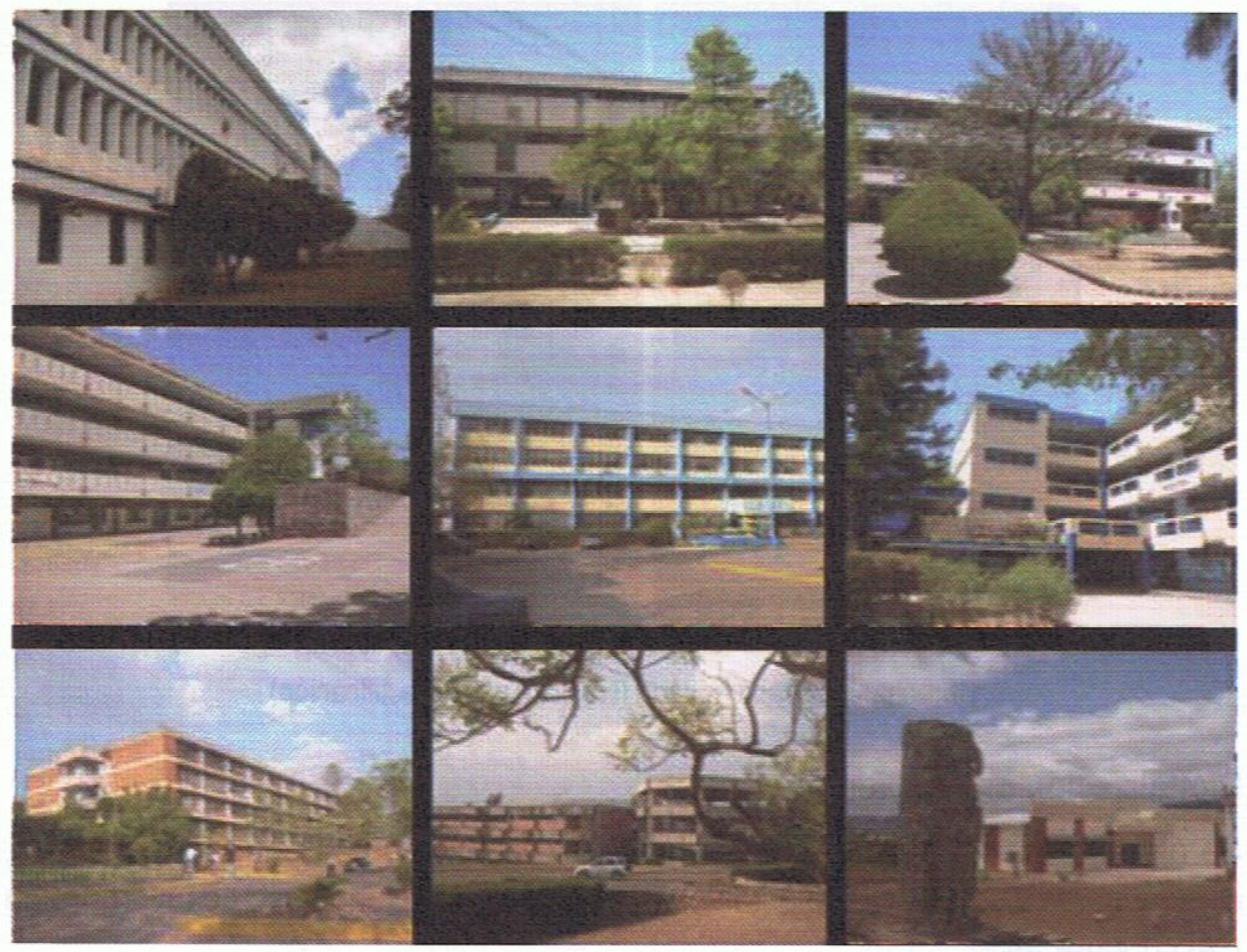

Figura1.- Fotografias de edificios dentro del campus universitario

Proceso de edición de imágenes de fachadas (ortorrectificación y limpieza digital de imágenes)

Luego de tomadas las fotografías, fue necesario seleccionarlas para posteriormente procesarlas digitalmente y transformar la proyección de perspectiva a proyección plana. Después se les dio una limpieza digital con un programa de edición de imágenes (Adobe Photoshop o Corel PhotoPaint) con el objetivo de eliminar de la fotografía todo elemento que dificulte la visibilidad y apreciación clara de la fachada (Figura 2). 

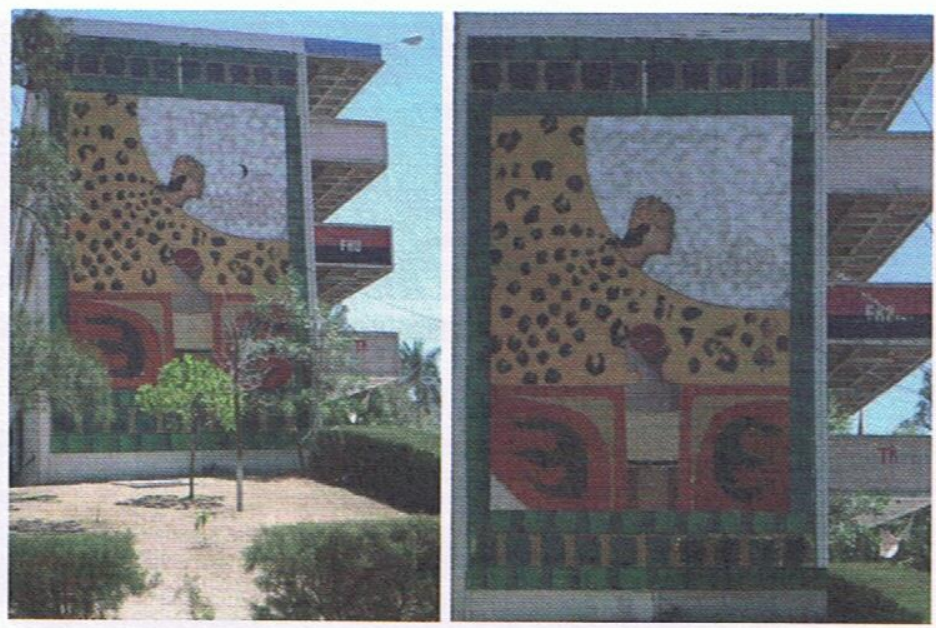

Figura 2.- Izquierda: fotografía original (perspectiva).

Derecha: fotografía editada (limpieza y ortorrectificación)

\section{Digitalización de fachadas}

Se digitalizaron de manera precisa todas las fachadas, considerando la escala, componentes y detalles arquitectónicos. Esto se hizo haciendo uso de un programa CAD (Figura 3).

En esta etapa se hizo uso del documento Levantamiento e inventario de los edificios de la Ciudad Universitaria, proporcionado por la VOAE, en el cual se muestran las características físicas de cada edificio dentro de la UNAH. También se utilizó, en los casos que fue necesario, la información vectorial del SIG del Departamento de Ciencia y Tecnologías de la Información Geográfica en la Facultad de Ciencias Espaciales.

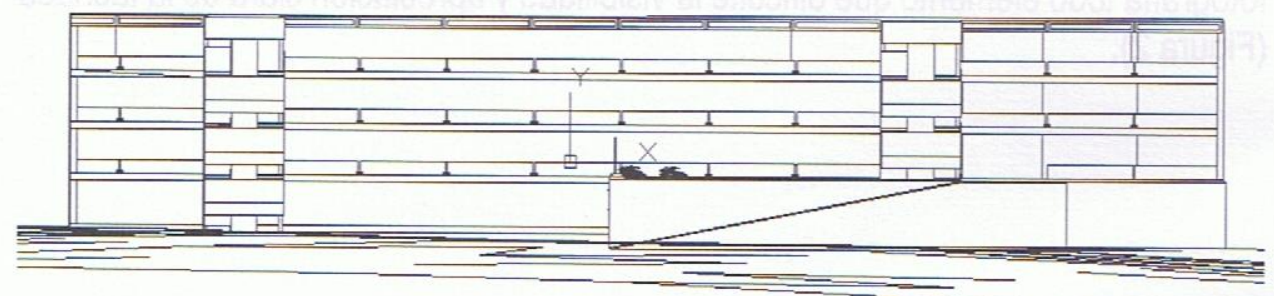

Figura 3.- Digitalización de fachadas mediante sistema CAD (edificio de Derecho UNAH) 


\section{Generación de volúmenes en 3D}

En esta actividad se generó el volumen de cada edificación (Figura 4) a partir de la planta de techos digitalizada para cada edificio. Esto se realizó utilizando el programa Sketchup 7.0, en el cual se importó previamente el MDT desde Google Earth, lo que permitió referenciar cada planta de edificios a un sistema de coordenadas real.

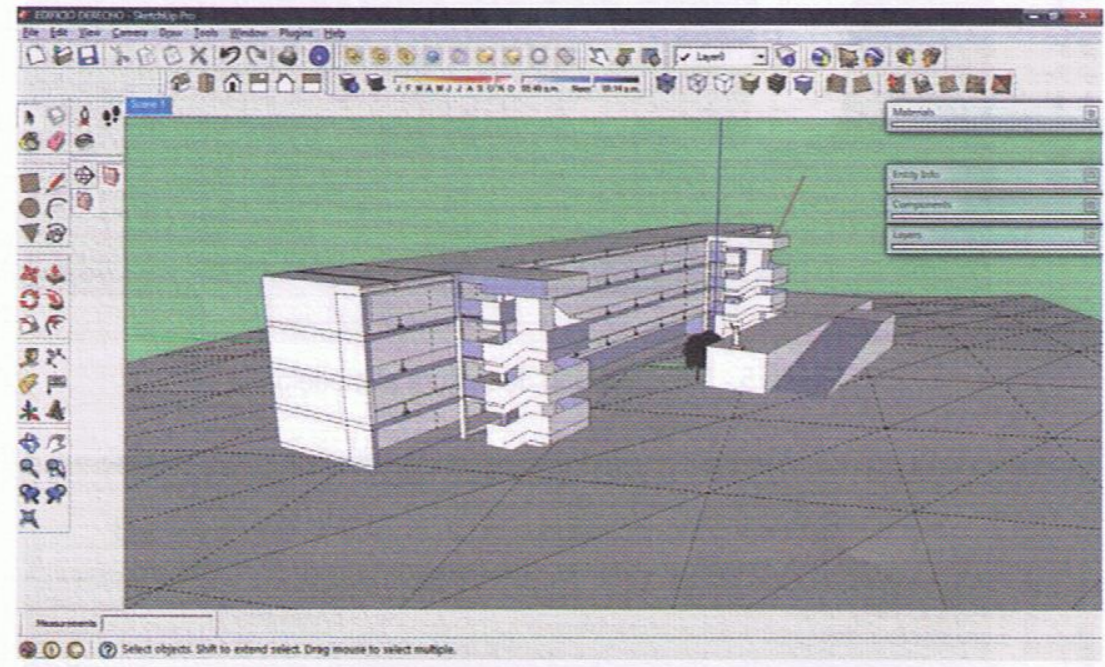

Figura 4.- Modelado 3D del edificio de la Facultad de Derecho

\section{Renderizado de materiales y texturas fotográficas rectificadas}

Una vez generado el volumen del edificio, se procedió a importar las texturas de cada fachada desde las fotografías editadas hasta cada una de las caras del modelo ajustando su posición y escala (Figura 5).

Luego se procedió a ocultar las aristas de la geometría del modelo con la opción "Hidden Geometry" del programa Sketchup (Figura 6). 


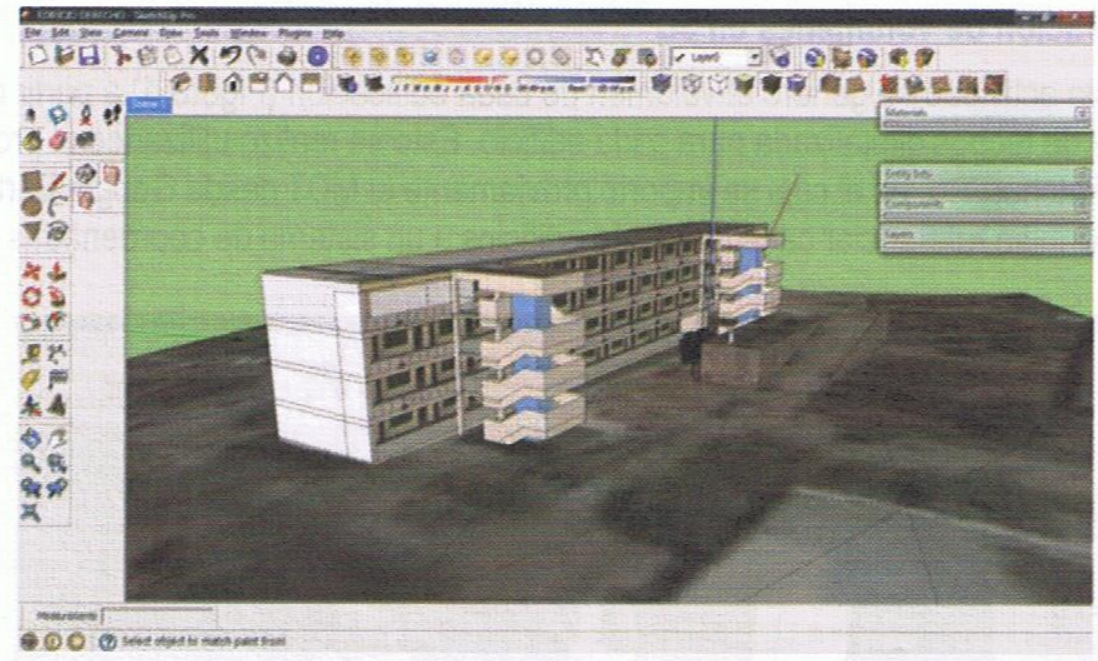

Figura 5.- Incorporación de textura al modelo

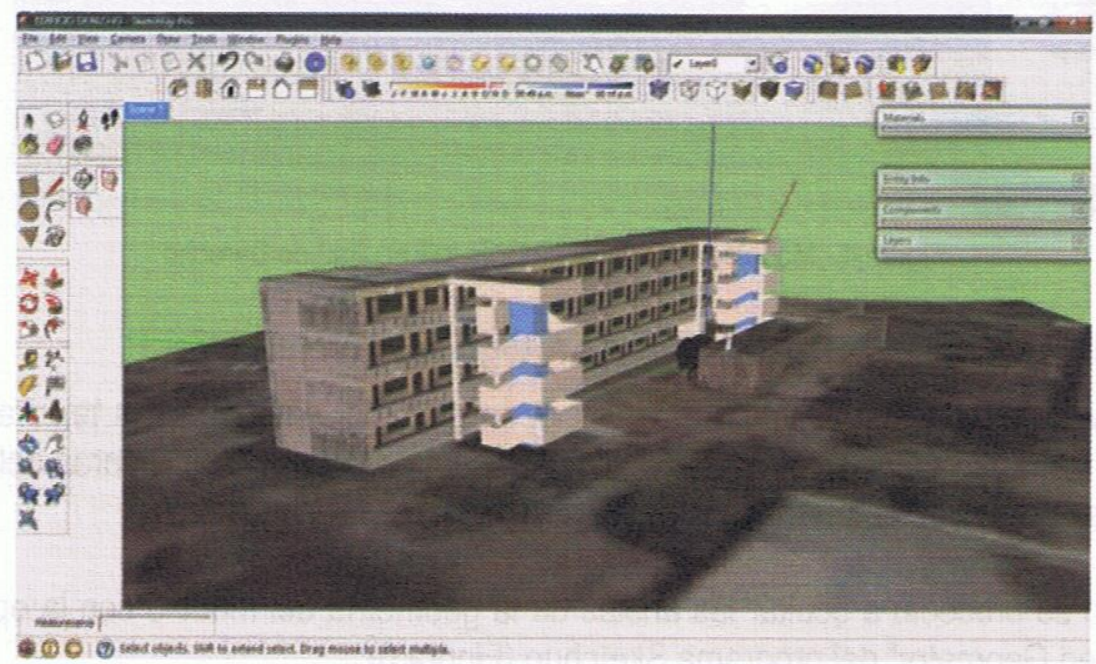

Figura 6.- Modelo con geometría oculta

Además de lo anterior, fue necesario depurar todos los elementos duplicados e innecesarios generados durante el modelado así como los layers o capas que no se utilicen, esto con el propósito de reducir lo más posible el tamaño del archivo.

\section{Completado de la escena}

Se procedió a la creación y edición de diferentes entornos: desde fondos artificiales con una determinada iluminación, hasta entornos reales construidos en base a mo- 
delos de elevación que representan fielmente la orografía del terreno. En este caso se utilizó el entorno tridimensional y fotorrealista de la plataforma Google Earth, donde se puede percibir el horizonte montañoso de la zona (Figura 7).

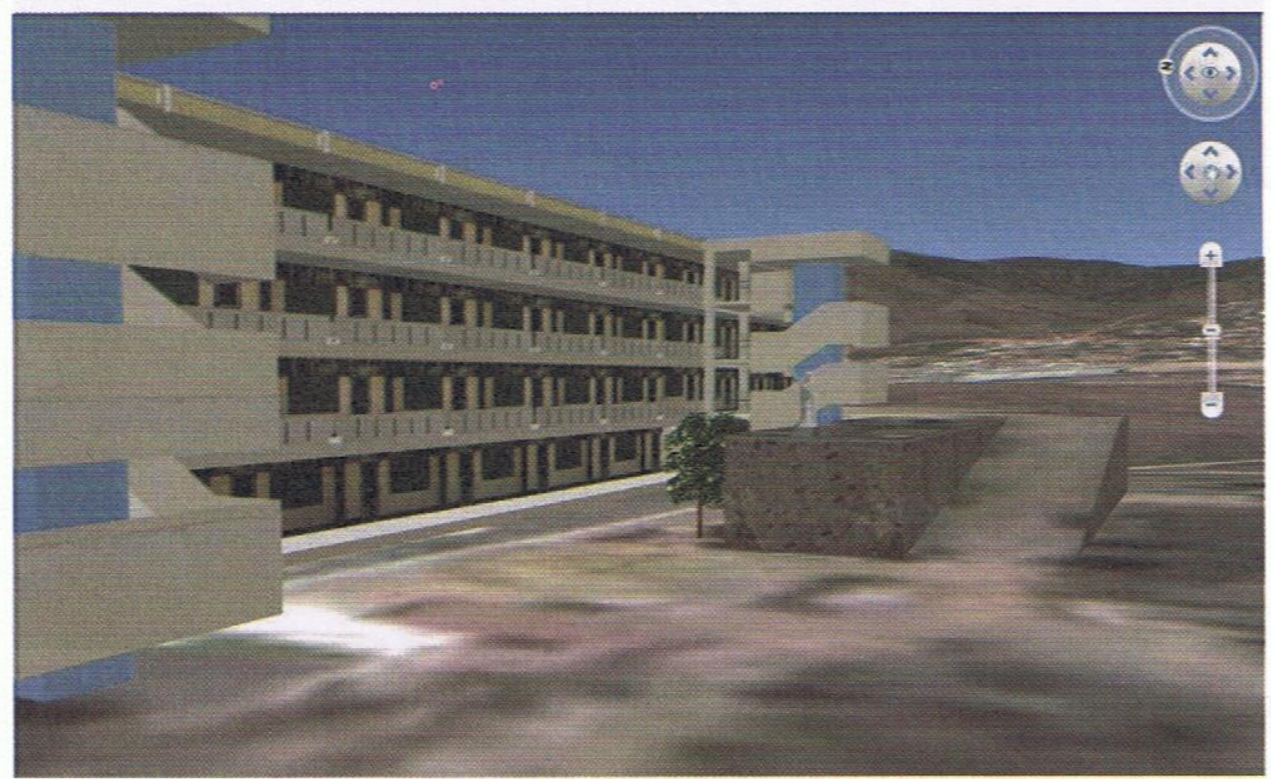

Figura 7.- Entorno fotorrealista del modelo proporcionado en la plataforma de Google Earth

\section{Incorporación al SIG de los modelos tridimensionales de edificaciones}

En esta etapa se procedió a exportar los volúmenes $3 \mathrm{D}$ de las edificaciones al modelo de terreno desarrollado en el SIG. Para esto se utilizaran puntos $(X, Y)$ de ubicación en cada una de ellas, definidas en un sistema de coordenadas, el cual puede estar asociado a un determinado modelo 3D: sistema local, o a un grupo de modelos 3D: sistema global, que nos permitirán cualquier manipulación espacial: rotación, escalado y traslación de los mismos (Figura 8). 


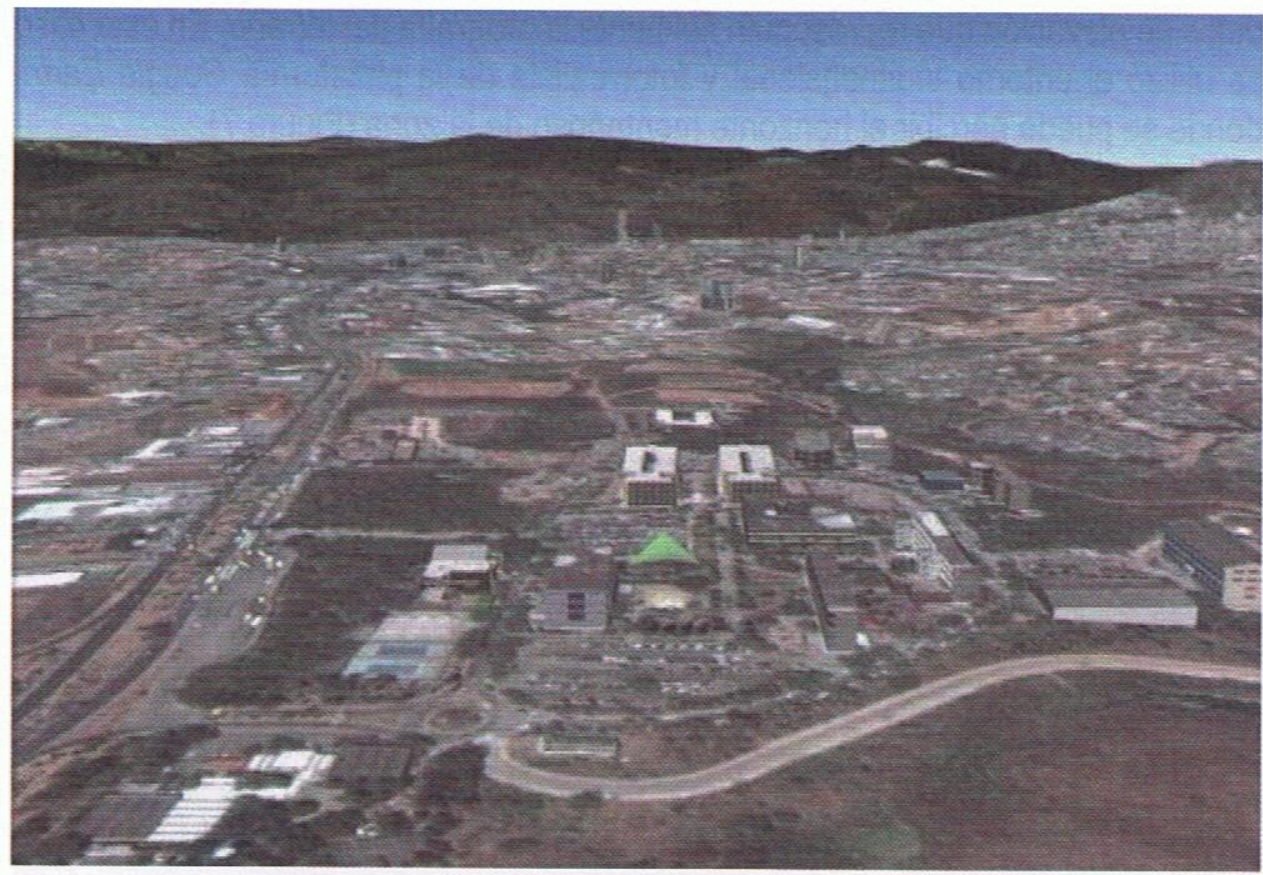

Figura 8.- Incorporación a modelo digital de terreno

\section{Tomas del movimiento y recorridos sobre el modelo}

En esta etapa se procedió a definir las rutas del recorrido y ambientación por las diferentes calles proyectadas en el modelo 3D en el SIG. Para esto se utilizaron opciones especializadas en el programa de SIG que permiten grabar el movimiento y definir rutas.

La inmersión en la escena de una cámara virtual y la manipulación de sus diferentes parámetros: focal, eje fotográfico y punto de vista nos permite obtener fotografías virtuales desde cualquier posición en la escena 3D, el fotograma virtual resultante puede ser almacenado y utilizado en posteriores análisis de perspectiva.

Esto comprendió que una vez exportados todos los edificios modelados a la plataforma de Google Earth (MDT y entorno fotorrealista), fue posible generar marcas de posición (Figura 9) que permitieron realizar recorridos virtuales sobre el campus universitario. Mediante un programa de captura de video (Camtasia Studio) se lograron generar tomas de movimiento en formato avi o .mpeg-4 (Figura 10). 


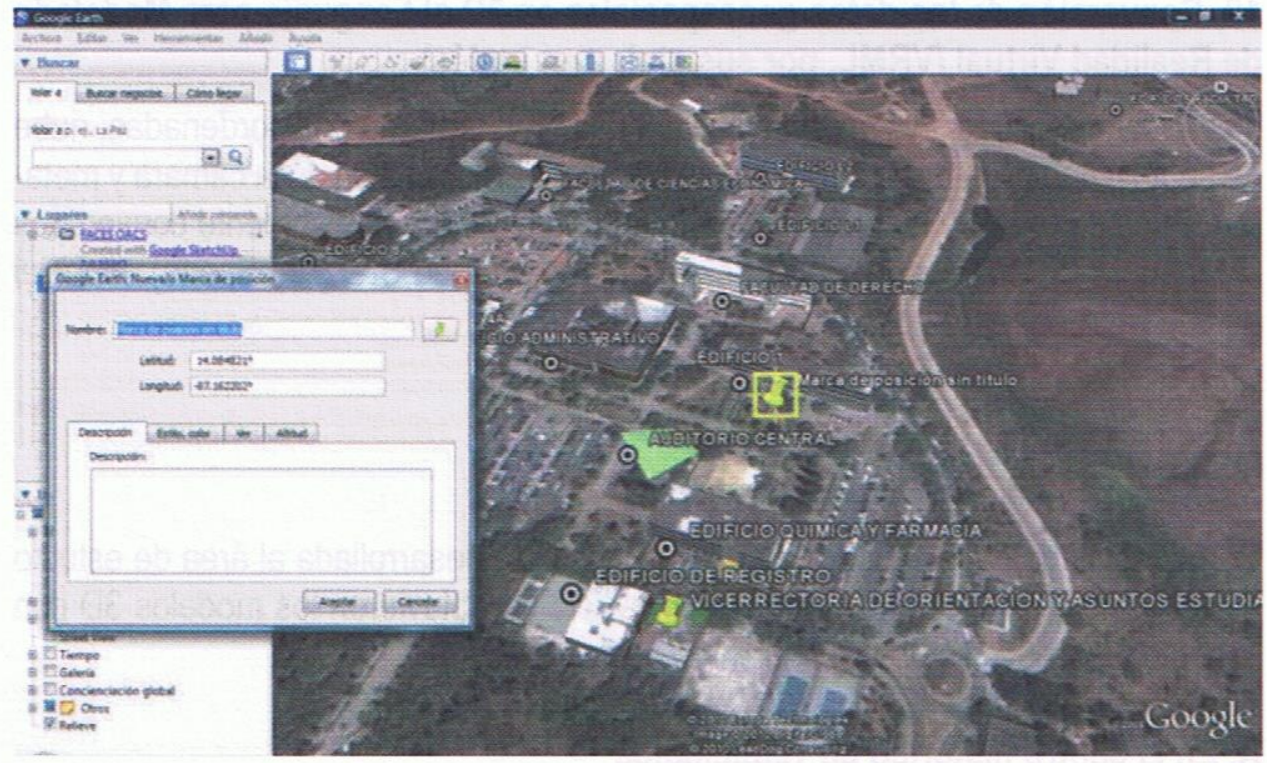

Figura 9.- Colocación de marcas de posición a cada edificio

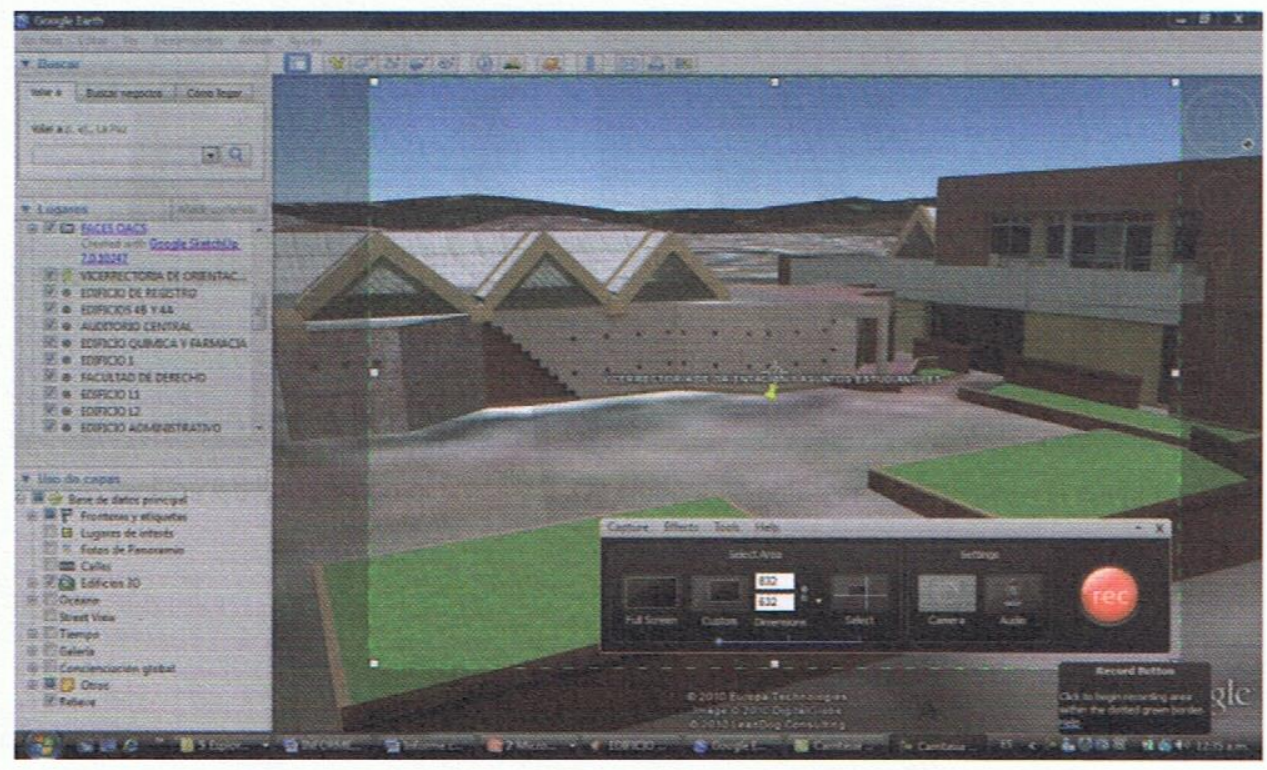

Figura 10.- Captura de video con el programa Camtasia Studio 
10. Conversión de los datos geoespaciales en 3D al Lenguaje para Modelado de Realidad Virtual (VRML, por sus siglas en inglés)

Los datos geoespaciales fueron constituidos por: el sistema de coordenadas, nube de puntos, líneas de fuga, entidades geométricas, información de la cámara y metadatos como colores y materiales. Igualmente, fueron automáticamente convertidos al lenguaje VRML exportándolos desde el programa de SIG (Arc Scene) especial para la representación de modelos en 3D.

\section{Resultados}

Como resultado de la aplicación de la metodología desarrollada al área de estudio seleccionada, en esta nueva fase del proyecto se obtuvieron los modelos $3 \mathrm{D}$ con aspecto fotorrealistas de las siguientes edificaciones:

\section{A. En el centro histórico de Tegucigalpa}

\section{Edificio de la Catedral de Tegucigalpa}

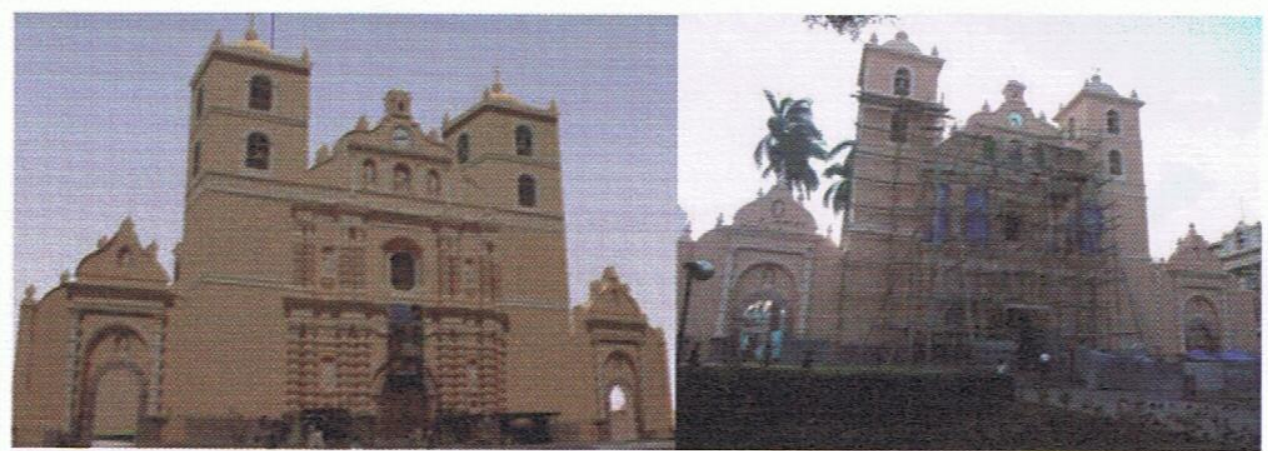

Figura 11.- Izquierda: fotograma de modelo \#D. Derecha: fotografia real del edificio 


\section{Iglesia "Los Dolores" de Tegucigalpa}

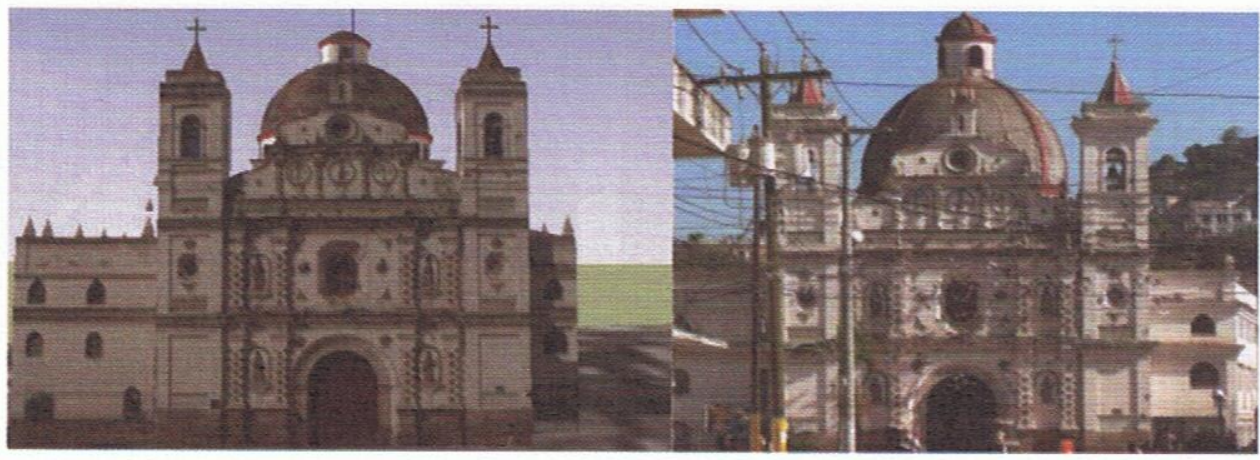

Figura 12.- Izquierda: fotograma de modelo \#D. Derecha: fotografia real del edificio

\section{Antigua Casa Presidencial (Museo Histórico de la República)}

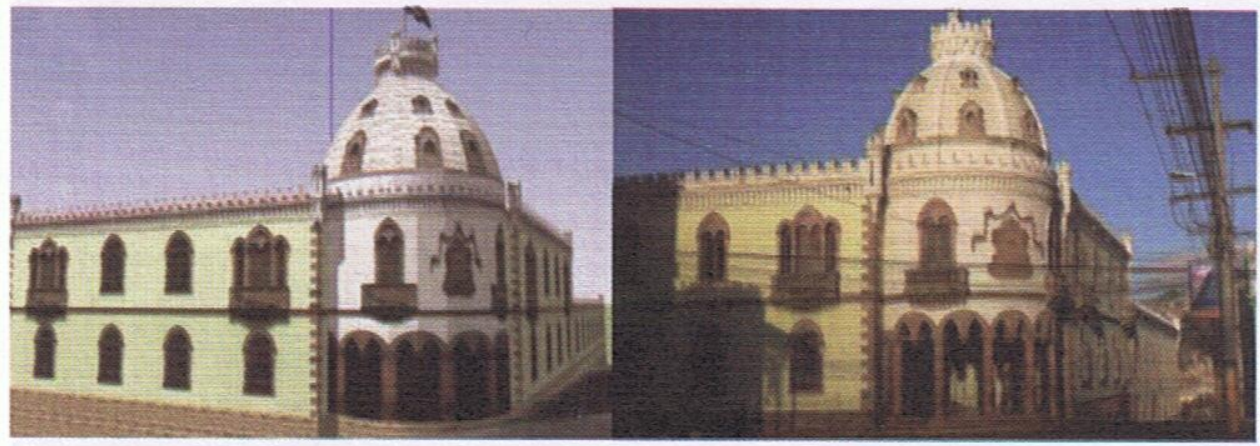

Figura 13.- Izquierda: fotograma de modelo \#D. Derecha: fotografía real del edificio

\section{Teatro Nacional "Manuel Bonilla"}

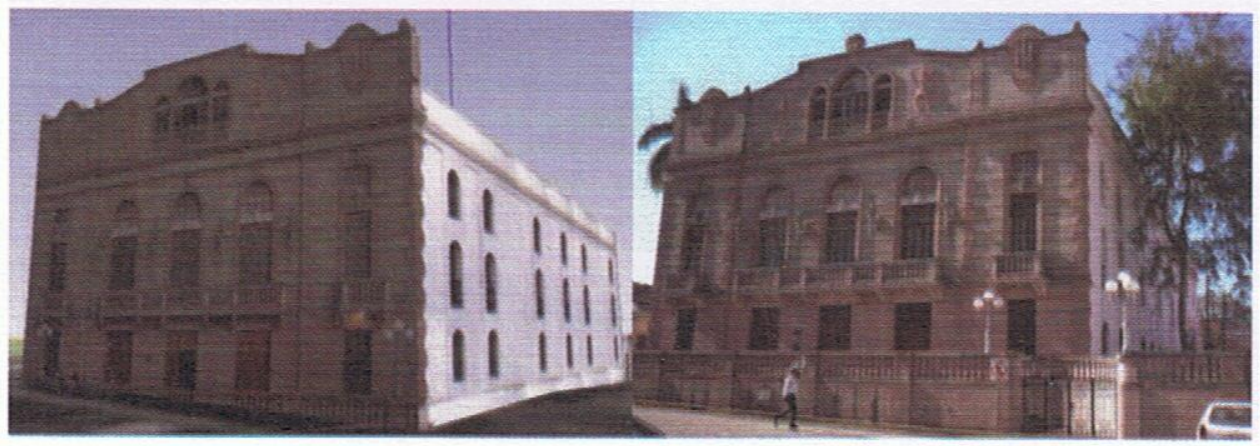

Figura 14.- Izquierda: fotograma de modelo \#D. Derecha: fotografía real del edificio 


\section{Edificio del Congreso Nacional}

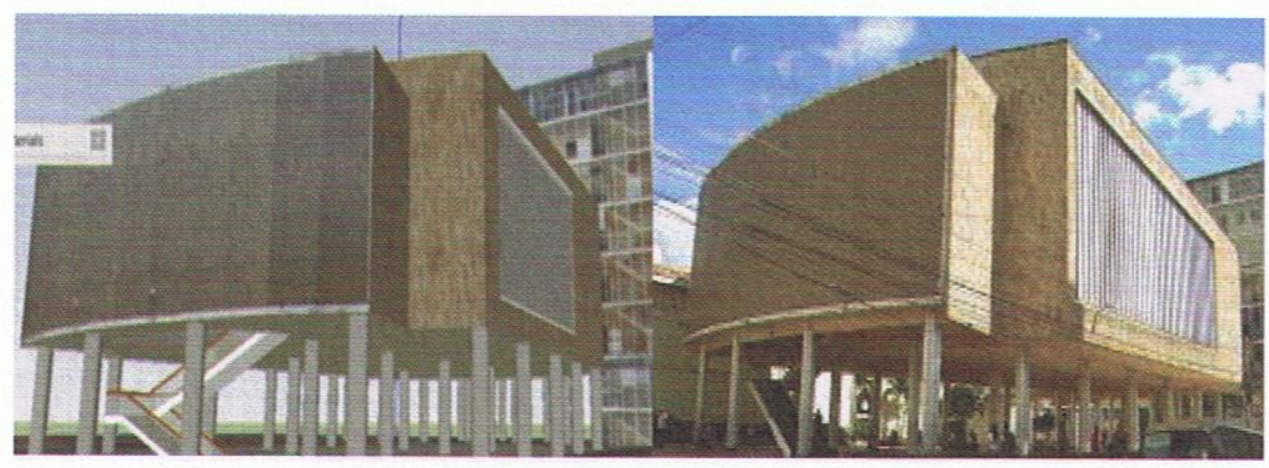

Figura 15.- Izquierda: fotograma de modelo \#D. Derecha: fotografía real del edificio

\section{B. En Ciudad Universitaria}

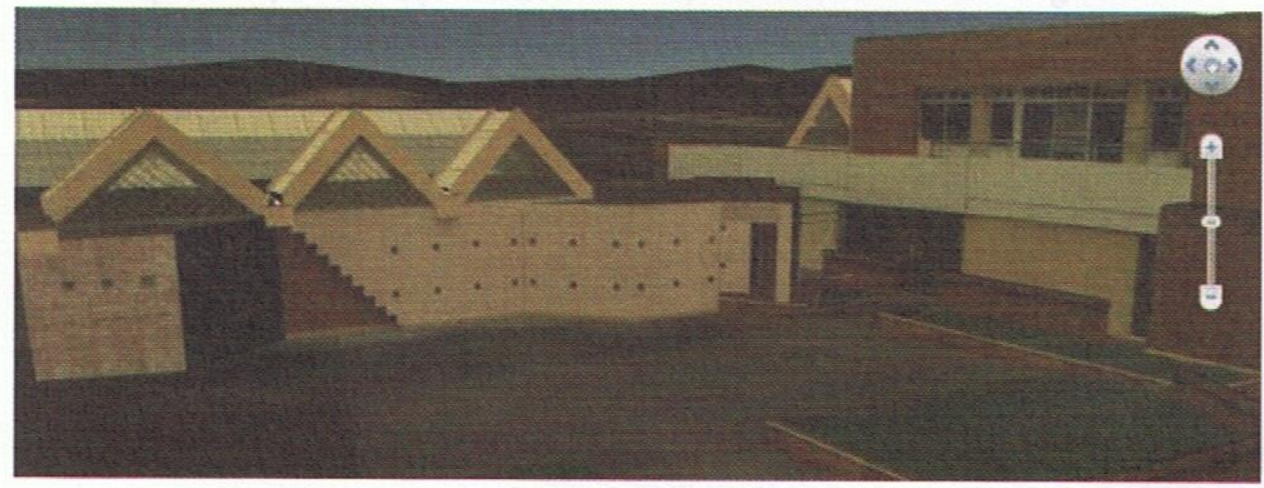

Figura 16.- Vicerrectoría de Orientación y Asuntos Estudiantiles (VOAE)

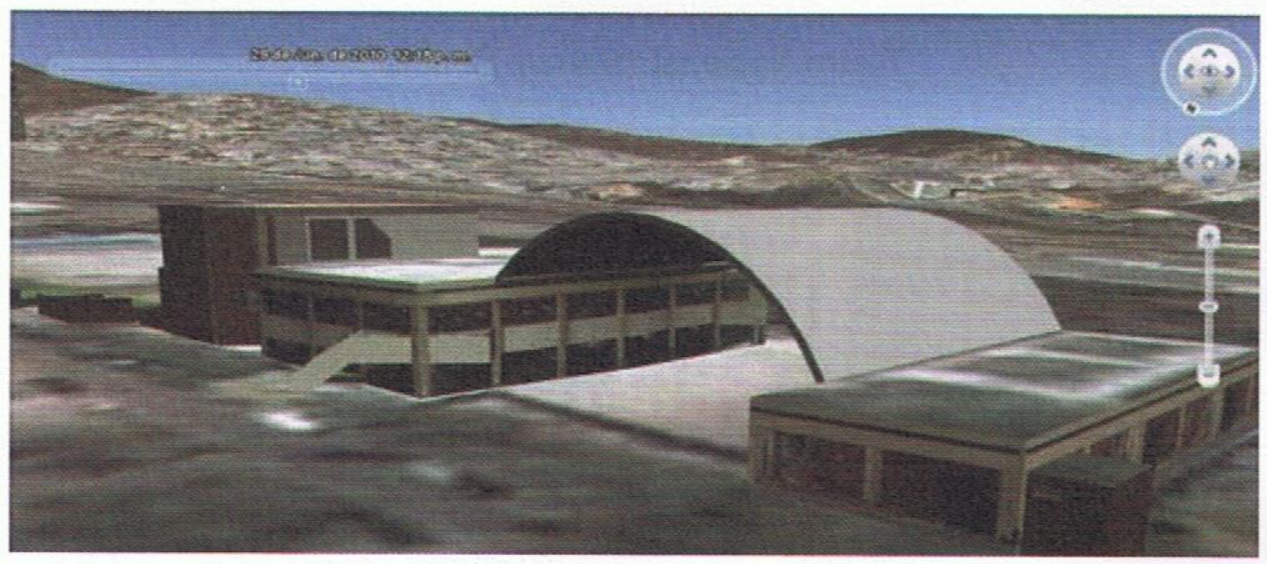

Figura 17.- Edificio de Registro 


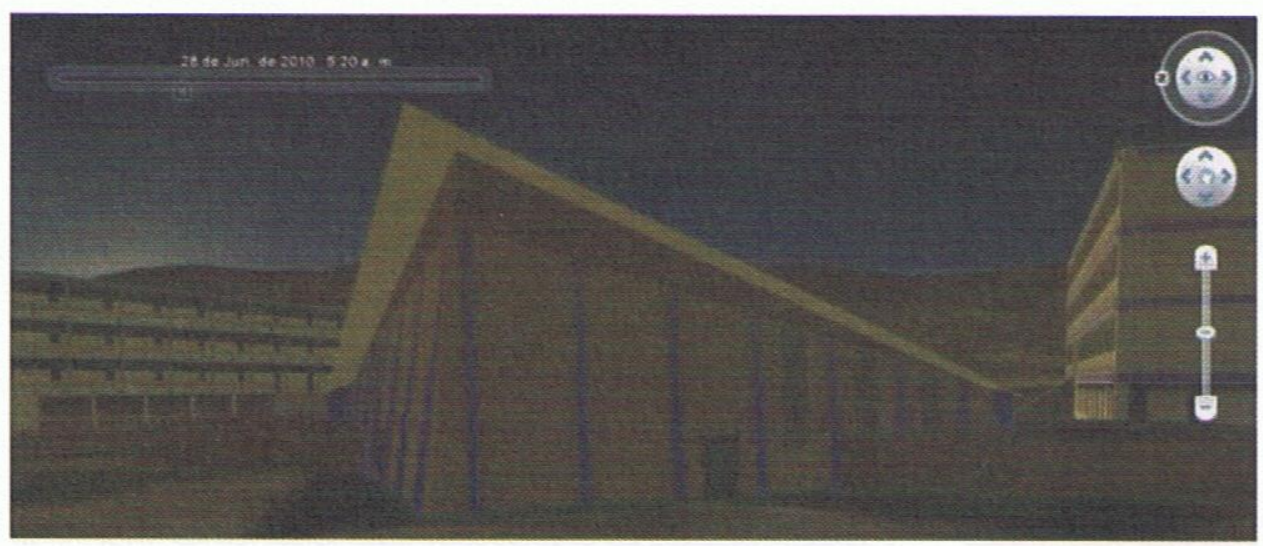

Figura 18.- Auditorio Central "Juan Lindo"

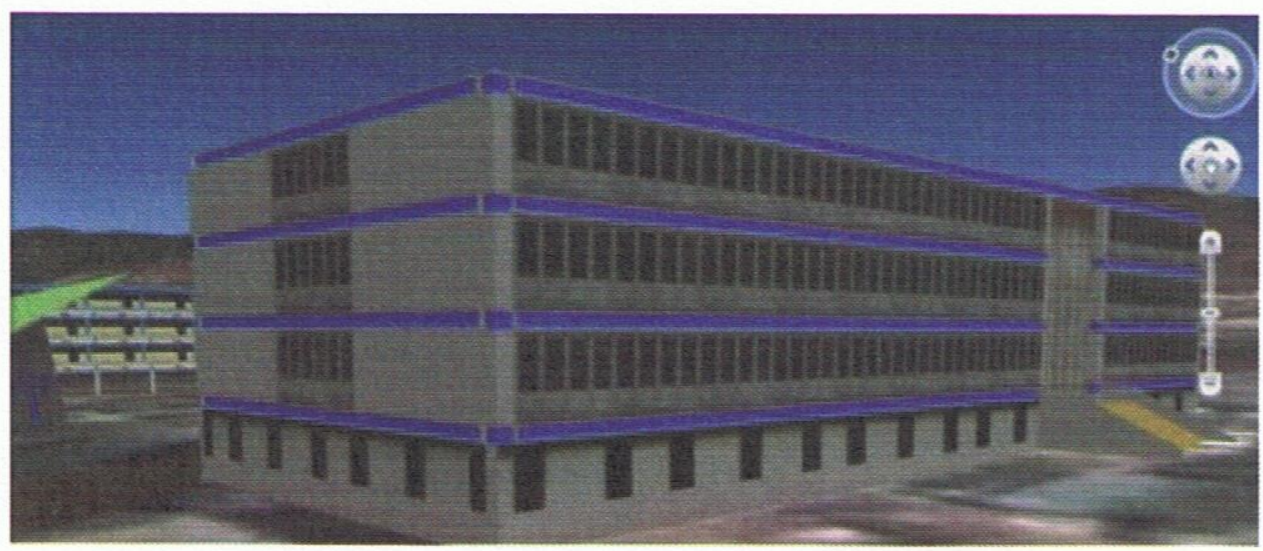

Figura 19.- Antiguo edificio de Química y Farmacia

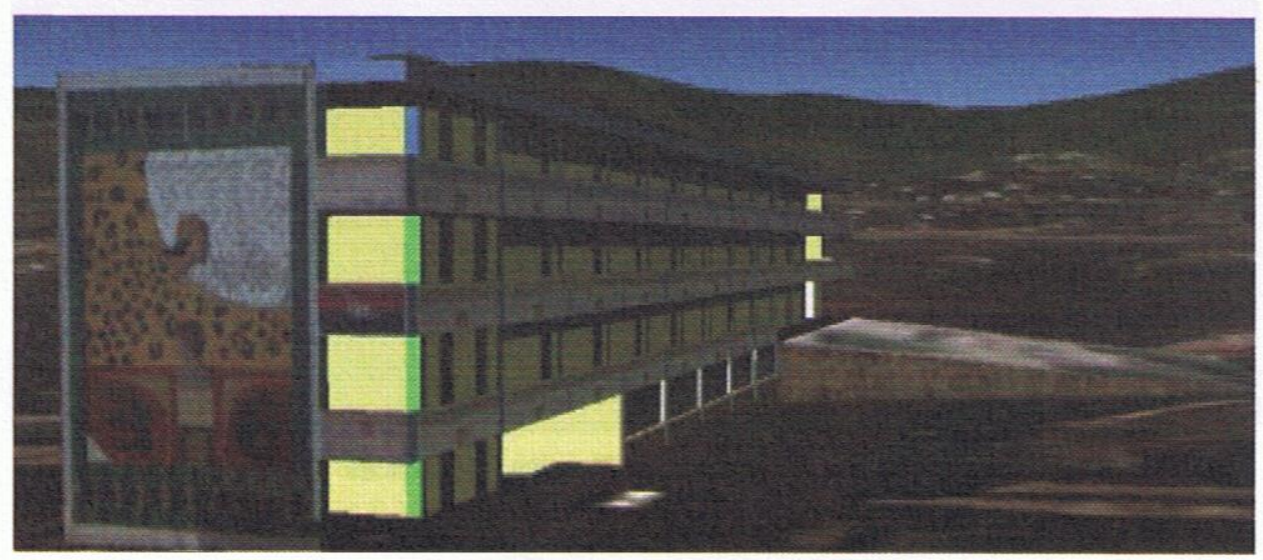

Figura 20.- Edificio 1 


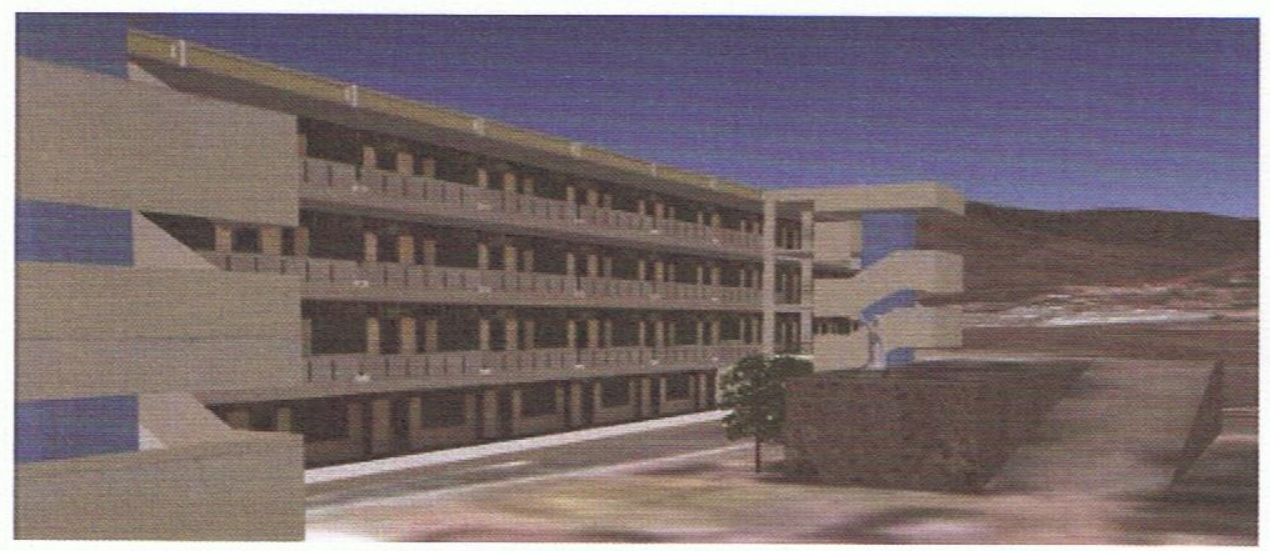

Figura 21.- Facultad de Derecho

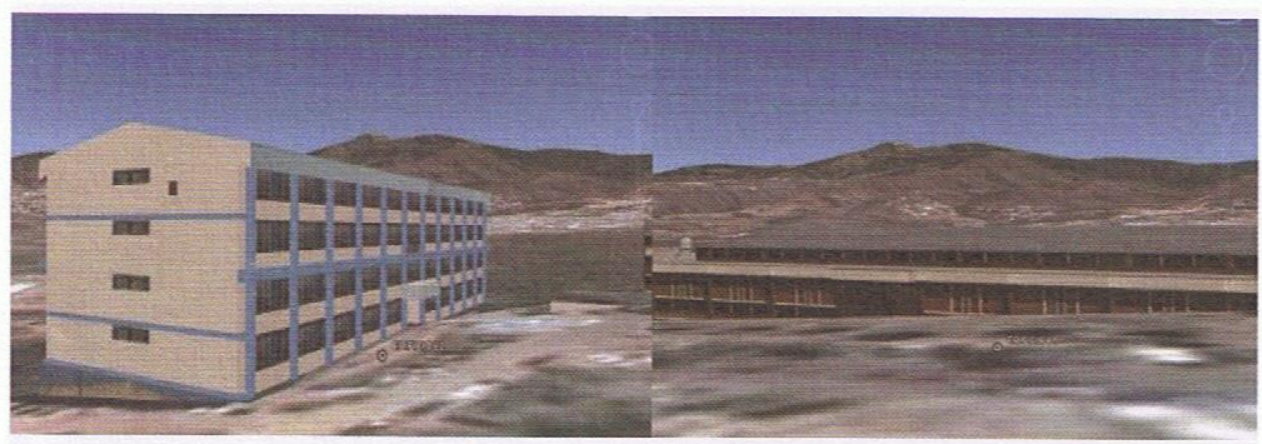

Figura 22.- Edificio $L 1$ y $L 2$

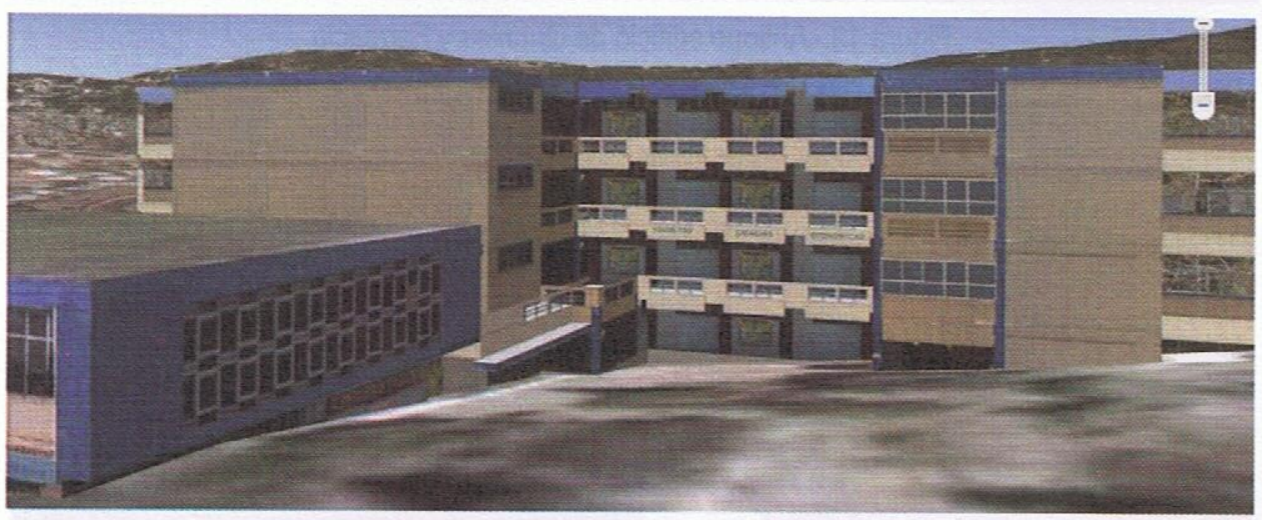

Figura 23.- Facultad de Ciencias Económicas 


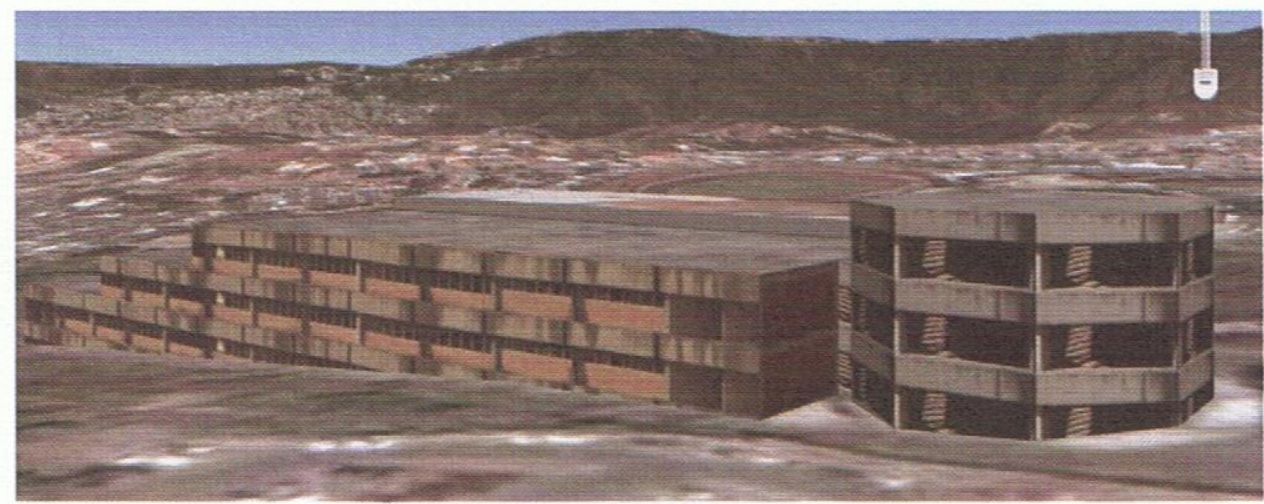

Figura 24.- Edificio 6

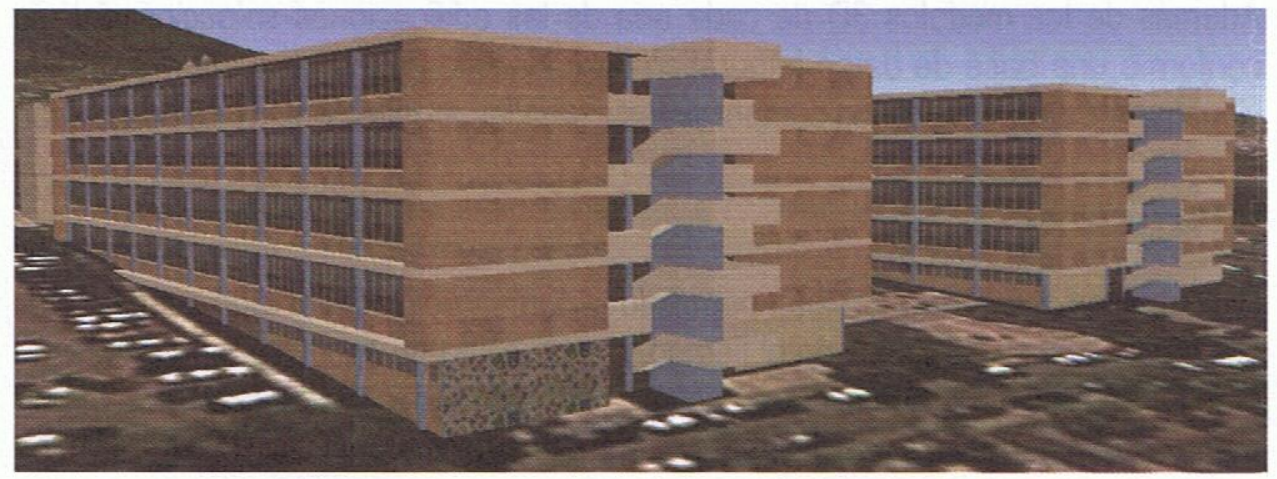

Figura 25.- Edificios de aulas $4 A$ y $4 B$

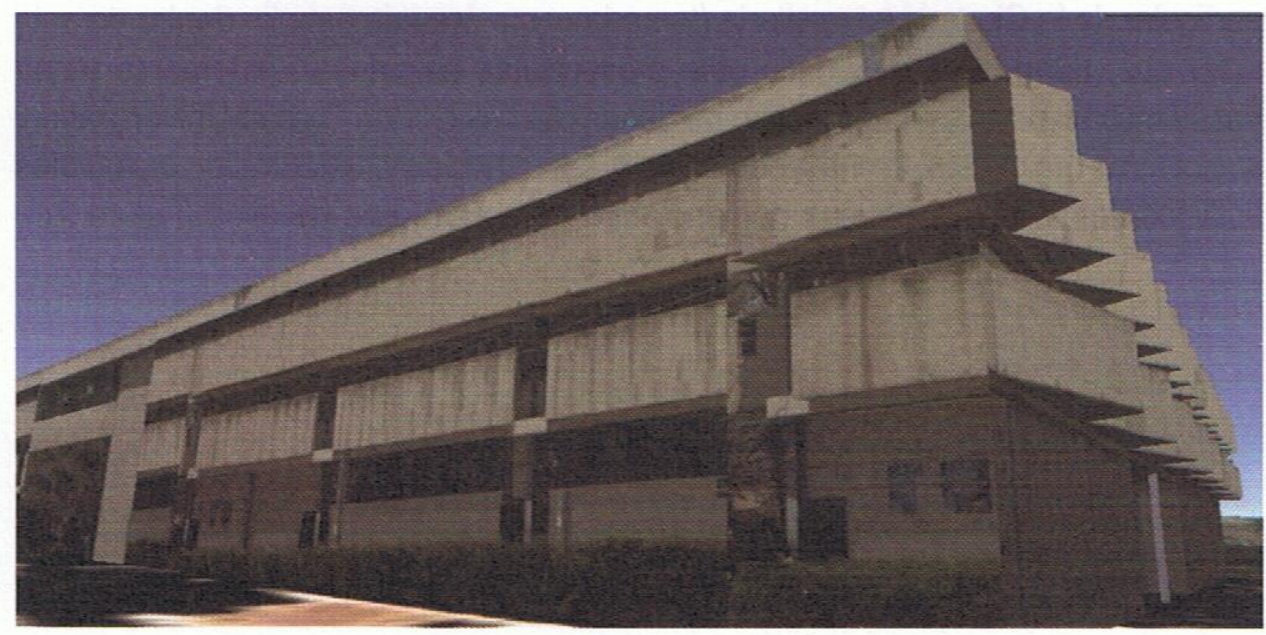

Figura 26.- Edificio Administrativo 


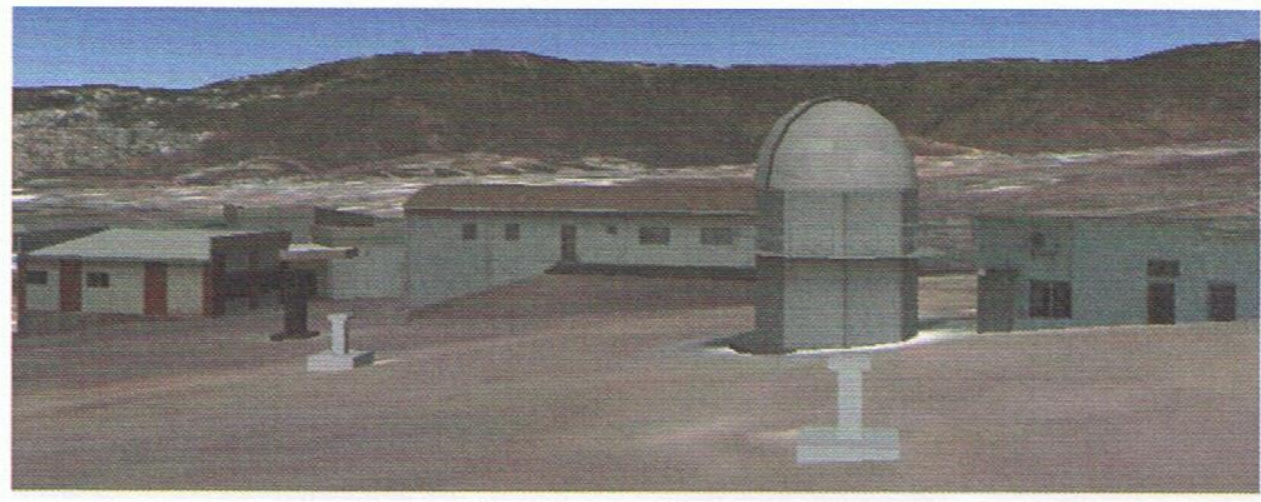

Figura 27.- Facultad de Ciencias Espaciales (FACES)

Además de los modelos 3D de cada una de las edificaciones seleccionadas se conformó una base de datos fotográfica de cada uno de los edificios registrando visualmente cada uno de los componentes y detalles arquitectónicos de su exterior.

\section{Discusión}

Los modelos acá generados han permitido la comparación del estado actual de las edificaciones y su evolución en el tiempo, siendo esto uno de los instrumentos y temas de análisis dentro de la disciplina de la conservación y restauración de monumentos. También esto se vuelve un instrumento muy útil para futuras actuaciones sobre el patrimonio tangible de una ciudad, como sucede en de la reorganización funcional de edificios, remodelación y planes de desarrollo urbano. Tal es el caso particular de la Ciudad Universitaria (tomada como área de estudio dentro de esta fase) que, durante se desarrolló este proyecto, se ejecutaba fuertemente y con pasos muy significativos el proceso de desarrollo físico en la Ciudad Universitaria y sus centros regionales, lo cual además de la construcción y restauración de muchos edificios derivó en una nueva nomenclatura para cada uno de ellos (Figura 28). 


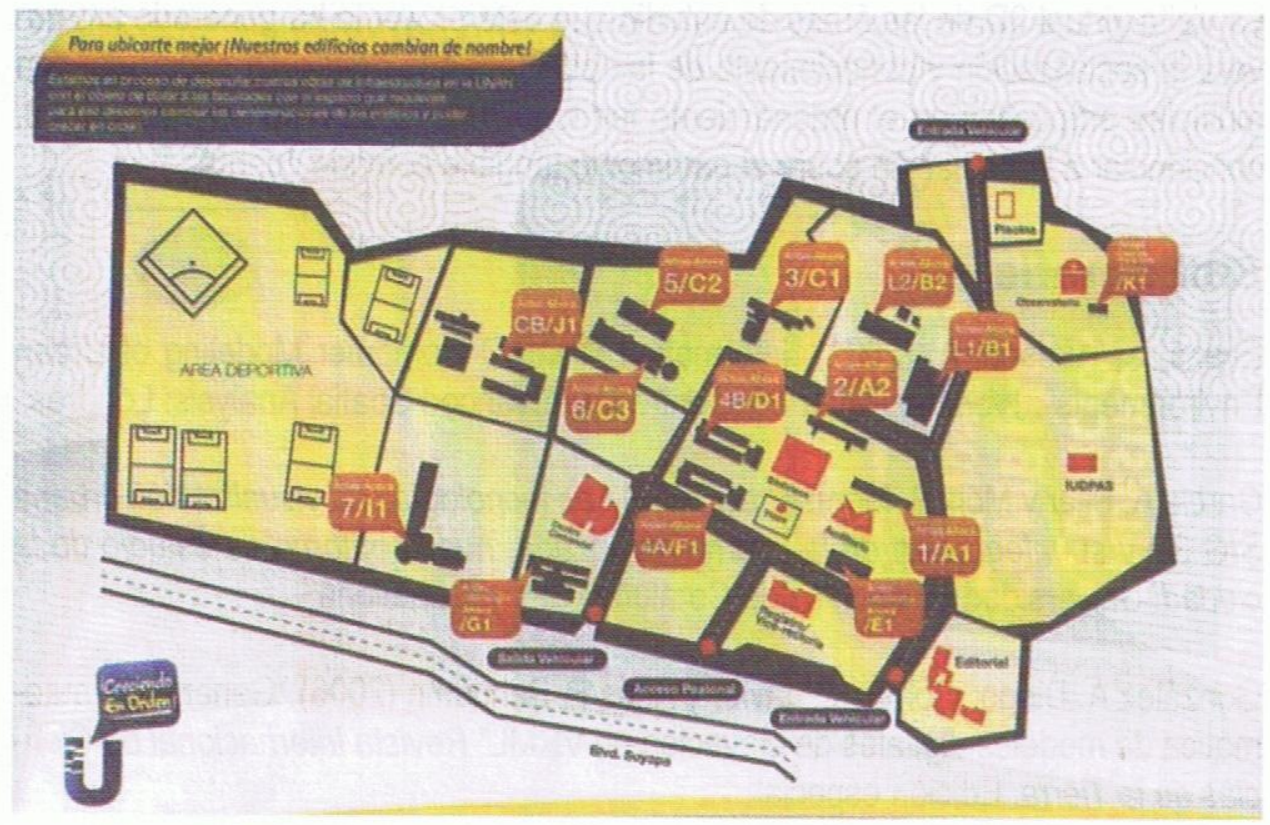

Figura 28.- Mapa de Ciudad Universitaria con la nueva nomenclatura de los edificios.

En este sentido, se vislumbra que el modelado de realidad virtual vinculado al SIG para la gestión de centros históricos brinda una plataforma excelente para el estudio de urbes históricas y conjuntos urbanos, ya que potenciar la aplicabilidad de las herramientas de análisis y visualización geoespacial.

\section{Conclusiones}

La historia arquitectónica de las edificaciones dentro del centro histórico de Tegucigalpa y la Ciudad Universitaria de la UNAH puede ser mejor ilustrada a través de estos modelos 3D y mejor descrita y analizada con su incorporación a los sistemas de información geográfica.

El modelo tridimensional georreferenciado de las instalaciones de la UNAH representa una herramienta muy útil en el proceso de desarrollo físico de la misma, ya que en él se puede proyectar y analizar infraestructura nueva y remodelaciones que se pretendan desarrollar en el futuro. 
La visita virtual 3D de las áreas de estudio que este proyecto ha generado promoverá la socialización y conocimiento de las edificaciones dentro de cada una, con múltiples propósitos en el ordenamiento territorial, con el objetivo de, entre otros, concienciar a la población sobre el patrimonio tangible con que cuenta.

\section{Bibliografía}

Evans, S, Hudson, A. (2001) "Information Rich 3D Computer Modeling of Urban Environments". Working Paper 35. Centre for Advanced Spatial Analysis: Londres.

García A, Pilar y Moix B. Montserrat (2003) Las tecnologías de visualización urbana SIG 3D y su integración en la Internet avanzada, nuevo entorno de estudio de la ciudad. Universidad Politécnica de Cataluña (UPC): Barcelona.

González A. Diego, Gómez L. Javier y Arias P. Benjamín (2006) "Generación automática de modelos digitales de elevación en VRML" Revista Internacional de Ciencias de la Tierra. Edición especial.

Moreno E. (2009) "Modelo de realidad virtual del centro histórico del Distrito Central basado en análisis espacial con sistemas de información geográfica" Revista Ciencia y Tecnología. UNAH: Tegucigalpa. 